\title{
The effect of continuous positive airway pressure therapy on the prevalence of masked hypertension in obstructive sleep apnea patients
}

\author{
Milan Sovaa , Eliska Sovova ${ }^{b}$, Milada Hobzovaa, Jana Zapletalovac , Monika Kamasova ${ }^{b}$, Vitezslav Kolek ${ }^{a}$
}

\begin{abstract}
Background and Aim. Obstructive sleep apnea (OSA) is a common cause of secondary arterial hypertension. Masked hypertension $(\mathrm{MH})$ is defined as normal office blood pressure and abnormal results in $24 \mathrm{~h}$ ambulatory blood pressure monitoring (ABPM). The aim of this study was to evaluate the effect of CPAP therapy on the prevalence of MH in patients with OSA.

Methods. 43 patients (40 men) were included, average age $54.2 \pm 10.5$ years. All underwent sleep study (PG or PSG) with a diagnosis of OSA indicated for CPAP treatment, average apnea-hypopnea index (AHI) 60.6 \pm 23 .6. Patients were treated with CPAP for one year. Ambulatory blood pressure monitoring was performed before and after one year of treatment. Results. Masked hypertension was initially present in $25(58.1 \%)$ and in 26 (60.5\%) patients after one year of CPAP therapy. However, there was a statistically significant improvement in BP for all evaluated intervals of ABPM with the exception of systolic pressure during the daytime.

Conclusions. Masked hypertension was very prevalent in these patients with OSA. The CPAP treatment for one year however had no affect on prevalence of masked hypertension although there was a positive effect of CPAP treatment on blood pressure for all assessed intervals of ABPM with the exception of systolic BP during daytime.
\end{abstract}

Key words: masked hypertension, obstructive sleep apnea, continuous positive airway pressure, ambulatory blood pressure monitoring

Received: June 10, 2014; Accepted with revision: November 18, 2014; Available online: December 22, 2014

http://dx.doi.org/10.5507/bp.2014.063

${ }^{a}$ Department of Respiratory Medicine, Faculty of Medicine and Dentistry, Palacky University Olomouc and University Hospital Olomouc, Czech Republic

${ }^{b}$ Department of Internal Medicine I - Cardiology, Faculty of Medicine and Dentistry, Palacky University Olomouc and University Hospital Olomouc

'Department of Biophysics, Faculty of Medicine and Dentistry, Palacky University Olomouc

Corresponding author: Milan Sova, e-mail: milan.sova@email.cz

\section{INTRODUCTION}

Obstructive sleep apnea syndrome (OSA) is a common chronic disorder with clinically serious consequences. The prevalence of this disorder is reported to be somewhere between $3 \%$ to $7 \%$ in middle aged individuals ${ }^{1}$ and it is considered an independent risk factor for cardiovascular diseases, development and worsening of arterial hypertension ${ }^{2,3}$, diabetes ${ }^{4}$, and heart rhythm disorders ${ }^{3}$. The relationship between OSA and arterial hypertension is under intense investigations the latter doubles the risk of cardiovascular diseases (including myocardial infarction), congestive heart failure, ischemic and hemorrhagic stroke, renal failure, and diseases of the peripheral arteries ${ }^{5}$.

Arterial hypertension is found in around 50\% of patients with OSA. By comparison, the common prevalence of arterial hypertension in a population of similar patients without OSA is $30 \%\left(\right.$ ref. $\left.^{6}\right)$. OSA increases the risk of arterial hypertension independently of other factors - The Sleep Heart Health Study showed a linear correlation between systolic and diastolic blood pressure levels and severity of OSA ( ref. $^{7}$ ). In these patients, arterial hypertension is present mostly during the night and it has a non-dipper type (blood pressure level during daytime is the same or higher than during the night $)^{8}$. In patients with resistant arterial hypertension, OSA is present in up to $83 \%$ of patients 9 . These results indicate that in all patients with resistant arterial hypertension (patients taking at least triple combination of antihypertensive drugs, of which one is a diuretic) OSA should be ruled out.

Masked hypertension ( $\mathrm{MH}$ ) is defined as a blood pressure level which is higher during home measurement ( $24 \mathrm{~h}$ blood pressure monitoring (ABPM) or self monitoring) than casual blood pressure level measured in the office ${ }^{10}$. A common cause of masked hypertension is nocturnal hypertension which we are not able to assess without ABPM. An arbitrary threshold of masked hypertension has been defined as a blood pressure level during the day > 135/85 mm Hg measured by ABPM (ref. ${ }^{11}$ ). Questionable is whether we can apply this term to patients who are already being treated for arterial hypertension. In 2013, the European Society of Hypertension issued a position paper on ambulatory blood pressure monitoring ${ }^{12}$ where the new term,- masked uncontrolled hypertension was suggested. This term should be reserved for patients with treated arterial hypertension which is not well controlled according to ABPM. The prevalence of masked hypertension in the general population is estimated to be 10 to $25 \%$ (ref..$^{11,13-14}$ ). Controversial remains the fact that mere assessment of blood pressure during the day does 
not detect nocturnal hypertension which then remains unrecognized. Mainly in patients with OSA, the prevalence of nocturnal hypertension can be high and it can worsen prognosis. To date few studies have evaluated the prevalence of $\mathrm{MH}$ in patients with OSA (ref. ${ }^{15-16}$ ). Common finding of these studies was that the prevalence of $\mathrm{MH}$ is higher in OSA patients than the general population ${ }^{15-16}$.

Continuous positive airway pressure (CPAP) ventilator is considered to be the most effective treatment modality for obstructive sleep apnea. Few studies of CPAP effects on blood pressure however have been done. Arterial hypertension was usually well compensated in these studies, the duration was usually quite short and the results are inconsistent ${ }^{17}$. The results of four metaanalyses of randomized studies were published. Bazzano et al. summarized 16 studies conducted between 1980 and 2006 (818 subjects). In these studies, they found a decrease in systolic blood pressure by $2.46 \mathrm{mmHg}$ and decrease in diastolic BP by $1.83 \mathrm{mmHg}$ (ref. ${ }^{18}$ ). Alajmi et al. performed metaanalysis of 10 studies ( 587 subjects) that used control groups. Blood pressure differences were small and insignificant but the authors described a trend to better blood pressure control with higher CPAP adherence ${ }^{19}$. Mo and He published a metaanalysis of 7 studies (471 subjects) and they used 4 weeks of CPAP therapy and ABPM as evaluation criteria. Changes in blood pressure were again small and significant for only diastolic blood pressure over $24 \mathrm{~h}^{20}$. Haentjens et al. evaluated 12 studies (572 subjects) where ABPM were performed and CPAP effects were compared with sham CPAP. Significant differences were found for mean BP and systolic BP during the night time. Results also depended on severity of sleep apnea and on therapy adherence ${ }^{21}$. We could summarize, that these studies showed slight and variable effect of continuous positive airway pressure on blood pressure level ${ }^{22}$.

According to the available literature only one small sample size study of CPAP effects on the prevalence of $\mathrm{MH}$ has been published ${ }^{15}$.

Kario et al. ${ }^{23}$ considered masked hypertension as a first step toward correct blood pressure compensation. If we assume that CPAP improves blood pressure, it should also reduce masked hypertension.

\section{AIM}

To assess the prevalence of masked and nocturnal hypertension in patients with OSA, evaluate the relation to parameters of OSA and assess the effects of one year of continuous positive airway pressure therapy (CPAP).

\section{MATERIALS AND METHODS}

\section{Sample}

43 patients ( 40 men) of average age $54.2 \pm 10.5$ years were enrolled in the study. The inclusion criterion was a moderate to severe (apnea- hypopnea index > 15) OSA with indications for continuous positive airway pressure therapy together with a diagnosis of arterial hypertension.
The following exclusion criteria were applied: low compliance with CPAP therapy (defined as CPAP usage $<4 \mathrm{~h} /$ night obtained from CPAP internal memory), left ventricle ejection fraction $<50 \%$, significant heart valve disorder, diagnosed cause of secondary arterial hypertension other than OSA, pulmonary fibrosis, chronic obstructive pulmonary disease stage III and IV according to GOLD 2011 classification, patients with central sleep apnea and Cheyne-Stokes breathing, patients taking medication that could interfere with the parameters followed in this study or any change (dose adjustment, change of medication) in their antihypertensive treatment.

\section{Physical examination}

Body mass index (BMI) and anthropometric parameters (body weight and height; neck, waist and hip circumference) were measured during physical examination and patients completed the Epworth sleepiness scale questionnaire.

\section{Blood pressure measurement}

Blood pressure was measured using a standard sphygmomanometer with regular (every 3 months) calibration according to guidelines ${ }^{24}$ and arterial hypertension borderline was defined as $140 / 90 \mathrm{mmHg}$.

Ambulatory blood pressure monitoring was done using the Spacelabs device (Spacelabs Healthcare). Measurements were made every 20 min during the daytime and every 30 min during the night. Mean systolic and diastolic blood pressure levels were measured during the following intervals: $24 \mathrm{~h}$, daytime, night. As target values the following average blood pressure levels were defined: 130/80 mm Hg over $24 \mathrm{~h} ; 135 / 85 \mathrm{~mm} \mathrm{Hg}$ during the daytime and $120 / 70 \mathrm{~mm} \mathrm{Hg}$ during the night ${ }^{25}$.

Ambulatory blood pressure was monitored at baseline and repeated after one year of CPAP therapy.

Two ad hoc definitions of masked hypertension were chosen.

D I. Normal office BP together with abnormal mBP (mean blood pressure) according to ABPM in any of the measured intervals.

D II. Normal office BP together with abnormal mBP according to ABPM measured during the daytime.

In this study we used the term masked hypertension as a synthesis of masked and masked uncontrolled hypertension according to the ESH position paper ${ }^{12}$ as this term was valid at the time and it is well-known to physicians. We assessed the prevalence of masked and nocturnal hypertension in the whole study group as did Baguet et al. ${ }^{16}$

Nocturnal hypertension (NH) was defined as $\mathrm{mBP}$ during night $>120 / 70 \mathrm{mmHg}$.

\section{Polysomnography, polygraphy}

All patients underwent standard overnight polysomnography (Alice 5, Respironics, USA) or respiratory polygraphy (Miniscreen, F+G, Germany). Recordings were manually rescored (using the American Academy of Sleep Medicine 2005 criteria) by one experienced physician (standard procedure in country of origin) with appro- 
Table 1. Parameters of OSA, clinical characteristics and their comparison after one year of CPAP treatment- sleep study using CPAP.

\begin{tabular}{lccc}
\hline & $\begin{array}{c}\text { Baseline } \mathrm{n}=43 \\
\text { Median, range }\end{array}$ & $\begin{array}{c}\text { One year } \mathrm{n}=43 \\
\text { Median, range }\end{array}$ & $P$ \\
\hline Apnea-hypopnea index & $59.2(11.8-114.3)$ & $4.0(0.0-30.6)$ & $<0.0001$ \\
Oxygen desaturation index & $66.3(12.6-118.4)$ & $10.0(1.0-57.3)$ & $<0.0001$ \\
Average night saturation (\%) & $91.0(64.0-95.0)$ & $93.5(82.0-96.0)$ & $<0.0001$ \\
\% of sleep time $<90 \% \mathrm{SpO}_{2}$ & $28.0(1.0-89.0)$ & $0.0(0.0-19.7)$ & $<0.0001$ \\
Epworth sleepiness scale & $10.0(1.0-21.0)$ & $5.0(0.0-12.0)$ & $<0.0001$ \\
Body mass index & $35.8(26.6-47.3)$ & $34.5(27.7-44.6)$ & 0.490 \\
\hline
\end{tabular}

priate certification issued by the national sleep medicine society. Standard definition of apnea (flow cessation $>10$ seconds) and hypopnea (flow limitation $>50 \%$ and blood oxygen saturation decrease $>3 \%$ ) were used. Apneas were classified as obstructive, mixed and central according to the presence or absence of respiratory efforts. The following parameters of the sleep apnea syndrome were further analyzed- apnea-hypopnea index (AHI), oxygen desaturation index (ODI), average night blood oxygen saturation $\left(\mathrm{SpO}_{2}\right)$, and percentage of sleep time when $\mathrm{SpO}_{2}<90 \%$. The sleep study using same method as at baseline was repeated after one year of CPAP therapy.

\section{Continuous positive airway pressure titration}

CPAP therapy was started after initial evaluation. Optimal therapy pressure was titrated using autoCPAP for three nights during which the patient was hospitalized as an inpatient. Regular CPAP therapy was started after establishing optimal pressure.

\section{Ethics committee approval}

All necessary institutional review board approvals with conducting this research and patient signed Informed consent document approved by the local Ethics Committee.

\section{Statistical analyses}

All statistical analyses were performed at the Department of Medical Biophysics of Palacky University Hospital by an experienced statistician using software SPSS v. 15.

The Wilcoxon paired test was used to compare continuous variables that were measured at baseline and after one year of CPAP therapy. Changes in the prevalence of $\mathrm{MH}$ and $\mathrm{NH}$ after one year were analyzed using the McNemar test. Spearman's correlation analysis was used to assess the relationship between average BP and parameters of OSA. Differences between patients with and without $\mathrm{NH}$ and $\mathrm{MH}$ in parameters of OSA were assessed using the Mann-Whitney U test. The normality of data was tested using the Shapiro-Wilk test. The significance level was 0.05 .

\section{RESULTS}

Parameters of OSA, clinical characteristics at baseline and after one year of CPAP therapy are presented in
Table 2. Overview of antihypertensive treatment, ACEi- angiotensin converting enzyme inhibitor,

ARB- angiotensin receptor blocker, CCB- calcium channel blocker.

\begin{tabular}{lc}
\hline Pharmacological group & $\begin{array}{c}\text { Antihypertensive treatment } \\
\mathrm{n}\end{array}$ \\
\hline $\mathrm{ACEi}$ & 21 \\
$\mathrm{ARB}$ & 11 \\
$\mathrm{CCB}$ & 14 \\
Diuretic & 17 \\
Centrally acting agent & 7 \\
\hline
\end{tabular}

Table 1. We have found significant decrease in all ABPM intervals with the exception of BP during daytime. We found a significant change in all of these parameters after one year of CPAP therapy $(P<0.0001)$ with the exception of BMI.

Baseline pharmacological treatment is presented in Table 2. Only 6 patients were not treated with anti hypertensives in the course of the study.

Table 3 shows office BP levels, ABPM results and comparisons. When we compared baseline values with the results of measurement after one year of CPAP therapy.

Rates of correct BP compensation and the prevalence of $\mathrm{MH}$ and $\mathrm{NH}$ are shown in Table 4. The McNemar test showed no significant change in the compensation of office BP ( $<140 / 90 \mathrm{mmHg}, P=0.299)$ and no significant change in the prevalence of MH DI $(P=1.000)$ and $\mathrm{MH}$ DII $(P=0.265)$.

Parameters of OSA in group with $(\mathrm{MH}+)$ and without ( $\mathrm{MH}-$ ) masked hypertension are showed in Table 5.

The relationship between nocturnal hypertension and parameters of OSA, showed no significant differences between patients with and without nocturnal hypertension (baseline and after one year of CPAP therapy) in AHI $(P=0.170 ; 0.691), \%$ of sleep $<90 \% \mathrm{SpO}_{2}(P=0.901 ; 0.983)$ and the average night $\mathrm{SpO}_{2}(P=0.531 ; 0.831)$. However; ODI was significantly higher in patients with nocturnal hypertension $(P=0.014)$ at baseline but not after one year of CPAP therapy $(P=0.983)$.

We also investigated the relationship between $\mathrm{MH}$ and parameters of OSA at baseline and after one year of CPAP therapy. We found no significant differences between patients with and without MH DI in AHI $(P=0.522$; 0.775$)$, 
Table 3. Office blood pressure, $24 \mathrm{~h}$ ambulatory blood pressure and their comparison after one year of CPAP treatment.

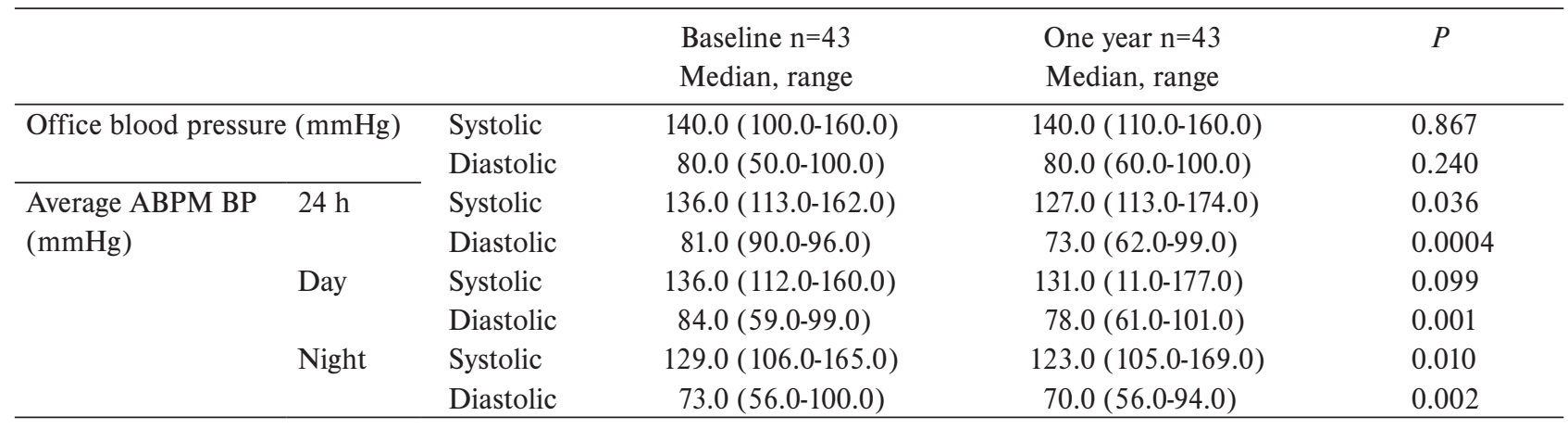

Table 4. Rates of blood pressure compensation and prevalence of masked and nocturnal hypertension.

\begin{tabular}{lccccc}
\hline & Baseline $(\mathrm{n})$ & $\%$ & One year $(\mathrm{n})$ & $\%$ & $P$ \\
\hline Office blood pressure & 31 & 72.1 & 36 & 83.7 & 0.299 \\
24 h systolic+diastolic & 11 & 25.6 & 23 & 53.5 & 0.015 \\
24 h systolic & 15 & 34.9 & 24 & 55.8 & 0.083 \\
24 h diastolic & 20 & 46.5 & 36 & 83.7 & 0.001 \\
Day systolic+diastolic & 17 & 39.5 & 26 & 60.5 & 0.084 \\
Day systolic & 19 & 44.2 & 26 & 60.5 & 0.195 \\
Day diastolic & 24 & 55.8 & 38 & 88.4 & 0.001 \\
Night systolic+diastolic & 9 & 20.9 & 12 & 27.9 & 0.616 \\
Night systolic & 10 & 23.3 & 16 & 37.2 & 0.240 \\
Night diastolic & 17 & 39.5 & 24 & 55.8 & 0.195 \\
All intervals & 7 & 16.3 & 10 & 23.3 & 0.589 \\
MH D I & 25 & 58.1 & 26 & 60.5 & 1.000 \\
MH D II & 19 & 44.2 & 13 & 30.2 & 0.265 \\
Nocturnal hypertension & 34 & 79.1 & 39 & 90.7 & 0.228 \\
White coat syndrome & 1 & 2.3 & 0 & 0 & 1.000 \\
\hline
\end{tabular}

ODI $(P=0.093 ; 0.691)$, average night $\mathrm{SpO}_{2}(P=0.796$; $0.435)$ and $\%$ of sleep $<90 \% \mathrm{SpO}_{2}(P=0.709 ; 0.933)$ or between patients with and without $\mathrm{MH}$ D II in AHI ( $P=0.541 ; 0.321)$, ODI $(P=0.174 ; 0.412)$, average night $\mathrm{SpO}_{2}(P=0.893 ; 0.857) \%$ of sleep $<90 \% \mathrm{SpO}_{2}(P=0.634$; $0.454)$.

The results of Spearman's correlation for baseline levels of average BP measured by ABPM are shown in Table 6 . They showed a positive correlation between levels of average systolic and diastolic blood pressure during the daytime $(0.318 ; 0.353)$ and ODI.

The Spearman's correlation analysis for average BP measured by ABPM after one year of CPAP therapy are shown in Table 7 . The analysis showed slightly negative correlation between average night $\mathrm{SpO}_{2}$ and average BP measured in the following intervals: 24 h systolic BP ($0.389)$, systolic BP during day (- 0.372), systolic BP during the night (-0.384).

\section{DISCUSSION}

Few studies have examined the prevalence of $\mathrm{MH}$ in patients with OSA. Our study showed very high prevalence of masked hypertension in patients with OSA, at baseline MH (high BP in all ABPM intervals) was found in $25(58.1 \%)$ patients. In studies done by Drager et al.
Table 5. OSA parameters in MH groups, AHI- apnea- hypopnea index, ODI- oxygen desaturation index.

\begin{tabular}{lcc}
\hline & \multicolumn{2}{c}{$\begin{array}{c}\text { OSA parameters } \\
\text { Median (range) }\end{array}$} \\
& MH I + & MH I - \\
\hline AHI & $59.2(25.0-106.3)$ & $57.5(11.8-114.6)$ \\
ODI & $70.0(12.6-117.0)$ & $56.3(15.0-118.4)$ \\
average night $\mathrm{SpO} 2(\%)$ & $91.0(84.0-94.0)$ & $91.0(64.0-95.0)$ \\
$\%$ of sleep < 90\% SpO2 & $23.1(1.0-79.0)$ & $28.5(6.0-89.5)$ \\
\hline
\end{tabular}

and Baquet et al. the prevalence of $\mathrm{MH}$ was slightly lower- $39 \%$ (ref. ${ }^{15}$ ) and $30 \%$ (ref. ${ }^{16}$ ). The difference can be explained by the above mentioned author's use of less strict criteria for $\mathrm{MH}$ (no high BP in the night interval). However; this is justified by the fact that nocturnal hypertension is very prevalent in patients with moderate to severe OSA and this may significantly worsen prognosis. When we use the same criteria as in the above studies (DII), the prevalence of $\mathrm{MH}$ it this group of patients is almost the same (44.2\%).

The prevalence of masked hypertension (DI and DII) had not changed significantly after one year of CPAP therapy. To the best of our knowledge, there is only one study on the effect of CPAP therapy on MH. Drager et al. showed a decrease in $\mathrm{MH}$ in patients treated with CPAP 
Table 6. Spearman's correlation analysis for baseline levels of average BP (blood pressure) measured by ABPM- Ambulatory blood pressure monitoring.

\begin{tabular}{lcccc}
\hline & AHI & ODI & Average night $\mathrm{SpO}_{2}$ & $\%$ of sleep time $<90 \% \mathrm{SpO}_{2}$ \\
\hline ABPM 24 h systolic & 0.136 & 0.300 & -0.096 & 0.018 \\
ABPM 24 h diastolic & 0.043 & 0.304 & -0.194 & 0.139 \\
ABPM Day systolic & 0.178 & 0.318 & -0.069 & -0.029 \\
ABPM Day diastolic & 0.147 & 0.353 & -0.179 & 0.123 \\
ABPM Night systolic & 0.101 & 0.243 & -0.156 & 0.087 \\
ABPM Night diastolic & -0.043 & 0.182 & -0.116 & 0.063 \\
\hline
\end{tabular}

Table 7. Spearman's correlation analysis for average BP (blood pressure) measured by ABPM (Ambulatory blood pressure monitoring) after one year of CPAP treatment.

\begin{tabular}{lcccc}
\hline & AHI & ODI & Average night $\mathrm{SpO}_{2}$ & $\%$ of sleep time $<90 \% \mathrm{SpO}_{2}$ \\
\hline ABPM 24 h systolic & -0.145 & 0.078 & -0.389 & -0.011 \\
ABPM 24 h diastolic & 0.153 & 0.093 & -0.105 & 0.026 \\
ABPM Day systolic & -0.241 & 0.055 & -0.372 & -0.005 \\
ABPM Day diastolic & 0.020 & 0.135 & -0.076 & 0.043 \\
ABPM Night systolic & -0.062 & 0.060 & -0.384 & 0.057 \\
ABPM Night diastolic & 0.117 & 0.061 & -0.053 & 0.032 \\
\hline
\end{tabular}

(ref. $\left.{ }^{15}\right)$. One difference and limitation of this study was that patients were treated with CPAP for only 3 months and only 18 patients without antihypertensive treatment were enrolled. The present study included patients with treated arterial hypertension without any change in their anti-hypertensive treatment during the course of the study. We also found a significant decrease in all intervals of blood pressure with the exception of systolic BP during the daytime. Some studies found a positive impact of CPAP therapy on blood pressure ${ }^{26-29}$. However; some studies question the impact of CPAP on BP level ${ }^{30-31}$. Currently, there is no consensus on whether CPAP decreases blood pressure in patients with obstructive sleep apnea.

CPAP improved blood pressure in this study but not the prevalence of masked hypertension. A possible explanation is the arbitrary thresholds of these two entities. There was a statistically significant reduction in blood pressure using CPAP but this was not large enough to normalize blood pressure over the whole day and night. There remains a question whether with longer follow up we would be able to find further reduction in BP and normalization of BP without change in antihypertensive treatment.

The prevalence of nocturnal hypertension was very high in these patients- $79 \%$. This finding is consistent with previously published data ${ }^{8}$. In our study the prevalence of nocturnal hypertension positively correlated with ODI. This could be evidence for the greater importance of oxygen desaturation in the pathophysiology of nocturnal hypertension than the simple presence of apnoic and hypopnoic pause. This is supported by the fact that higher ODI correlated with some measured intervals of BP (daytime).

This study contributes to understanding the effects of CPAP therapy on BP due to its long term nature and strict selection of patients. The main limitation is the absence of a control group CPAP therapy. In our opinion, it would be unethical to create such group because of the long term consequences of untreated OSA. The other limitation is use of polygraphy together with full polysomnography. However; the aim of the study was not to evaluate obstructive sleep apnea itself but the effect of CPAP therapy on blood pressure. In this case use of respiratory polygraphy is justifiable and had no influence on the final results. The sample size is relatively small mainly because frequent change of anti-hypertensive medication and subsequent exclusion of these patients.

Given the importance of $\mathrm{MH}$ in patients with OSA, we need to consider whether ABPM should be part of sleep study devices. With this approach we could diagnose arterial hypertension together with OSA and thus save costs needed for further evaluation of these patients. We would also be able to adjust the pharmacotherapy of arterial hypertension at the time of CPAP titration.

\section{CONCLUSIONS}

This study showed high prevalence of masked and nocturnal hypertension in patients with OSA. It showed a positive effect of CPAP therapy on blood pressure in patients without any change in their anti hypertensive treatment. The prevalence of masked and/or nocturnal hypertension did not change significantly with CPAP therapy however.

\section{ABBREVIATIONS}

ABPM, Ambulatory blood pressure monitoring; BMI, Body mass index; CPAP, Continuous positive airway pressure; DI, Masked hypertension definition I; DII, Masked hypertension definition II; mBP, Mean blood pressure; 
MH, Masked hypertension; NH, Nocturnal hypertension; ODI, Oxygen desaturation index; OSA, Obstructive sleep apnea.

\section{ACKNOWLEDGEMENT}

This study was supported by Palacky University internal grant IGA_LF_2014_027.

Author contributions: All authors contributed equally to preparing the manuscript.

Conflict of interest statement: None declared.

\section{REFERENCES}

1. Naresh M. Punjabi. The Epidemiology of Adult Obstructive Sleep Apnea. Proceedings of the American Thoracic Society 2008;5(2):13643.

2. Pedrosa RP, Drager LF, Gonzaga CC, Sousa MG, de Paula LK, Amaro AC, Amodeo C, Bortolotto LA, Krieger EM, Bradley TD, Lorenzi-Filho G. Obstructive sleep apnea: the most common secondary cause of hypertension associated with resistant hypertension. Hypertension 2011;58(5):811-7.

3. Jaffe LM, Kjekshus J, Gottlieb SS. Importance and management of chronic sleep apnoea in cardiology. Eur Heart J 2013;34(11):809-15.

4. West SD, Nicoll DJ, Wallace TM, Matthews DR, Stradling JR. Effect of CPAP on insulin resistance and $\mathrm{HbA} 1 \mathrm{c}$ in men with obstructive sleep apnoea and type 2 diabetes. Thorax 2007;62(11):969-74.

5. Fauci AS, Braunwald E, Kasper D. Harrison's Principles of Internal Medicine, 17th edd. McGraw Hill 2008, pp 1549-62.

6. Silverberg DS, Oksenberg A, laina A. Sleep-related breathing disorders a a major cause of essential hypertension: fact or fiction? Curr Opin Nephrol Hypertens 1998;7(4):353-57.

7. Nieto FJ, Young TB, Lind BK, Shahar E, Samet JM, Redline S, D'Agostino RB, Newman AB, Lebowitz MD, Pickering TG. Association of sleep- disorderes breathing, sleep apnea and hypertension in a large community-based study. JAMA 2000;283(14):1829-36.

8. Baquet JP, Barone-Rochette G, Pépin JL. Hypertension and obstructive sleep apnoea syndrome: current perspectives. J Hum Hypertension 2009;23(7):431-43.

9. Logan AG, Perlikowski SM, Mente A, Tisler A, Tkacova R, Niroumand $M$, Leung RS, Bradley TD. High prevalence of unrecognised sleep apnoea in drug resistant hypertension. J Hypertension 2001;19(12):2271-7.

10. Yuchiri Y, Bakris G. Recognition and management of masked hypertension: A review and novel approach. Journal of American Society of Hypertension 2013;7(3):244-52.

11. Pickering TG, Eguchi K, Kario K. Masked hypertension: A review. Hypertens Res 2007;30(6):479-88.

12. O'Brien E, Parati G, Stergiou G, Asmar R, Beilin L, Bilo G, Clement D, de la Sierra A, de Leeuw P, Dolan E, Fagard R, Graves J, Head GA, Imai Y, Kario K, Lurbe E, Mallion JM, Mancia G, Mengden T, Myers M, Ogedegbe G, Ohkubo T, Omboni S, Palatini P, Redon J, Ruilope LM Shennan A, Staessen JA, vanMontfrans G, Verdecchia P, Waeber B, Wang J, Zanchetti A, Zhang Y. European Society of Hypertension position paper on ambulatory blood pressure monitoring. J Hypertens 2013;31(9):1731-68.

13. Hansen TW, Kikuya M, Thijs L, Björklund-Bodegård K, Kuznetsova T, Ohkubo T, Richart T, Torp-Pedersen C, Lind L, Jeppesen J, Ibsen H, Imai Y, Staesse. Prognostic superiority of daytime ambulatory over conventional blood pressure in four populations: A meta-analysis of 7,030 individuals. J Hypertens 2007;25(8):1554-64.

14. Angeli F, Reboldi G, Verdecchia P. Masked hypertension: Evaluation, prognosis, and treatment. Am J Hypertens 2010;23(9):941-48.

15. Drager LF, Pedrosa RP, Diniz PM, Diegues-Silva L, Marcondes B, Couto RB, Giorgi DM, Krieger EM, Lorenzi-Filho G.The Effects of
Continuous Positive Airway pressure on Prehypertension and Masked Hypertension in Men With Severe Obstructive Sleep Apnea. Hypertension 2011;57(3):549-55.

16. Baguet JP, Lévy $P$, Barone-Rochette $G$, Tamisier R, Pierre H, Peeters M, Mallion JM, Pépin JL. Masked Hypertension in obstructive sleep apnea syndrome. Journal of Hypertension 2008;26(5):885-92.

17. Bradley TG, Floras JS. Obstructive sleep apnoea and its cardiovascular consequences. Lancet 2009;373(9657):82-93.

18. Bazzano LA, Khan Z, Reynolds K, He J. Effect of nocturnal nasal continous positive airway pressure on blood pressure in obstructive sleep apnoea. Hypertension 2007;50(2):417-23.

19. Alajmi M, Mulgrew AT, Fox J, Davidson W, Schulzer M, Mak E, Ryan CF, Fleetham J, Choi P, Ayas NT. Impact of continous positive airway pressure therapy on blood pressure in patients with obstructive sleep apnea hypopnoea: a meta analysis of randomized controlled trials. Lung 2000;185(2):67-72.

20. Mo L, He QY. Effect of long term continuous positive airway pressure ventilation on blood pressure in patients with obstructive sleep apnea hypopnea syndrome: a meta analysis of clinical trials. Zhonghua Yi Za Zhi 2007;87(17):1177-80.

21. Haentjens P, Van Meerhaeghe A, Moscariello A, De Weerdt S, Poppe K, Dupont A, Velkeniers B. The impact of continuous positive airway pressure on blood pressure in patients with obstructive sleep apnea syndrome: evidence from a meta analysis of placebo controlled randomized trials. Arch Intern Med 2007;167(8):757-64.

22. Somers VK, White DP, Amin R, Abraham WT, Costa F, Culebras A, Daniels S, Floras JS, Hunt CE, Olson LJ, Pickering TG, Russell R, Woo M, Young T. Sleep apnea and cardiovascular disease: An American Heart Association/American College of Cardiology Foundation Scientific Statement from the American Heart Association Council for High Blood Pressure Research Professional Education Commitee, Council on Clinical Cardiology, Stroke Council, and Council on Cardiovascular Nursing In Collaboration With the National Heart, Lung, and Blood Institute National Center on Sleep Disorders Research (National Institute of Health). J Am Coll Cardiol 2008;52(10):686-17.

23. Kario K, Saito I, Kushiro T, Teramukai S, Ishikawa Y, Hiramatsu K, Kobayashi F, Shimada K. Effect of the angiotensin II receptor antagonist olmesartan on morning home blood pressure in hypertension: HONEST Study at 16 weeks. J Hum Hypertens 2013;27(12):721-8.

24. Mancia G, De Backer G, Dominiczak A, Cifkova R, Tabard R, Germano G, Grassi G, Heagerty AM, Kjeldsen SE, Laurent S, Narkiewicz K, Ruilope L, Rynkiewicz A, Schmieder RE, Struijker Boudier HAJ, Zanchetti A. 2007 Guidelines for the management of arterial hypertension. Eur Heart J 2007;28:1462-36.

25. Myers, MG. Ambulatory blood pressure monitoring for routine clinical practice. Hypertension 2005;45(4):483.

26. Parati G, Lombardi C, Hedner J, Bonsignore MR, Grote L, Tkacova R, Lévy P, Riha R, Bassetti C, Narkiewicz K, Mancia G, McNicholas WT. Recommendations for the management of patients with obstructive sleep apnoea and hypertension. Eur Respir J 2013;41(3):523-38.

27. Becker HF, Jerrentrup A, Ploch T, Grote L, Penzel T, Sullivan CE, Peter $\mathrm{JH}$. Effect of nasal continuous positive airway pressure on blood pressure in patients with obstructive sleep apnea. Criculation 2003;107(1):68-73.

28. Bottini P, Taranto-Montemurro L, Novali M, Bettinzoli M, Roca E, Andreoli C, Bentivoglio M, Corda L, Tantucci C. Effects of CPAP on systemic hypertension in OSAH: a monocentric, observational, cohort study. Respir Med 2012;106(9):1329-34.

29. Durán-Cantolla J, Aizpuru F, Montserrat JM, Ballester E, Terán-Santos J, Aguirregomoscorta Jl, Gonzalez M, Lloberes P, Masa JF, De La Peña M, Carrizo S, Mayos M, Barbé F. Continuous positive airway pressure as treatment for systemic hypertension in people with obstructive sleep apnoea: randomised controlled trial. BMJ 2010;341(1):5991.

30. Phillips B, Shafazand S. CPAP and hypertension in nonsleepy patients. J Clin Sleep Med 2013;9(2):181-2.

31. Kasiakogias A, Tsioufis C, Thomopoulos C, Aragiannis D, Alchanatis M, Tousoulis D, Papademetriou V, Floras JS, Stefanadis C. Effects of continuous positive airway pressure on blood pressure in hypertensive patients with obstructive sleep apnea: a 3-year follow-up. J Hypertens 2013;31(2):352-60. 